NOTE: THIS IS THE “AUTHOR'S FINAL VERSION" TO BE ARCHIVED FOR PUBLIC ACCESS. PUBLISHED VERSION OF RECORD CAN BE FOUND AT:

Greyson, D. (2017). Health information practices of young parents. Journal of Documentation, 73(5), 7778-802. doi:10/1108/JD-07-2016-0089.

Health information practices of young parents

Bio: Devon Greyson, PhD MLIS, is a postdoctoral fellow at the Child \& Family Research Institute, University of British Columbia in Vancouver, Canada.

Acknowledgements: Dr. Greyson thanks Drs. Jean Shoveller, Joy Johnson, and Heather O'Brien for their supervision of this research. This work was funded by Vanier Canada and by Canadian Institutes of Health Research grants MOP-201209 and GIR-201212. 


\begin{abstract}
Despite societal investment in providing health information to young parents, little is known about the health information practices of young parents themselves.
\end{abstract}

This constructivist grounded theory study investigates the health information practices of young mothers and fathers (age 16-23) in Greater Vancouver, Canada. Data was collected over 16 months via individual interviews with 39 young parents ( 37 mothers, 2 fathers) and observations at young parent programs. Inductive analysis was iterative with data collection.

Young parent health information practices emerged, clustering around concepts of information seeking, assessment, and use, with sharing conceptualized as a form of use. Many young parents were sophisticated information seekers, and most were highly networked using mobile technology. While access to information was rarely a barrier, assessment of the large quantity of health-related information posed challenges.

These findings are not generalizable to all populations. Newly-identified information seeking practices such as defensive and subversive seeking should be explored further in future research.

Rather than focusing on quantity of information, health and information professionals trying to reach young parents should focus on fostering information literacy skills and building relationships as trusted information providers. 
Young parent experiences of social marginalization influenced their information practices and should be taken into consideration.

This first investigation of young parent information practices can guide services and resources for young parents, suggests that sharing might be conceptualized as a subset of use, and highlights new information seeking practices by marginalized individuals, such as defensive and subversive seeking. 


\section{Health information practices of young parents}

Due to the conceptualization of young pregnancy as a social and medical problem within Western modernity (Bonell, 2004; Furstenberg, 1976; Luker, 1997), and of teenagers and young adults as inexperienced and "risky" parents with poor decision making skills (Kelly, 2007; Shoveller and Johnson, 2006), a number of information-intensive health interventions have targeted young parents. Despite societal investment in providing health information to young parents, little is known about the health information practices of young parents themselves. Understanding the ways young parents seek, share, assess, and use health information in their everyday lives can improve interventions aiming to support pregnant and parenting youth.

This longitudinal, qualitative study explores the health information practices of a group of young mothers and fathers in Greater Vancouver, Canada. Using a combination of ethnographic observation of young parent services and in-depth individual interviews with 39 young parents themselves over the course of 16 months' time, young parents' information practices and experiences related to a variety of health issues were explored. Using constructivist grounded theory, analysis of the health-related information seeking, assessment, and use practices of this group of young parents emerged. The findings raise questions regarding the extent to which young parents as a group are different from other populations in terms of information access, literacy, and use, and therefore carries implications for how information interventions targeting young parents are best shaped and delivered.

\section{Literature}

While no published research to date has specifically investigated the information

practises of young parents $^{[1]}$, there are related literatures upon which this work may build. These include research and theory on adolescent everyday life information seeking and information 
practices, youth sexual and reproductive health information seeking, studies of (adult) parental information practices and behaviour, and investigations of contemporary Western practices of intensive parenting.

The body of LIS research focusing on adolescents' information practices is relatively small (Agosto, 2011), and within the extant literature everyday life studies of teens are in the minority, with much research focusing instead on school-related information needs and seeking (Bernier, 2007). Agosto and Hughes-Hassell (2006; 2006) took an everyday life information seeking (ELIS) approach (Savolainen, 1995), integrating multiple forms of qualitative data generated by urban teenagers in Pennsylvania, USA, to understand why such youth participated in everyday life information seeking. The resulting model integrated developmental psychology and information behaviour research by mapping common information needs to adolescent developmental needs such as social, physical, cognitive, and sexual self development (Agosto and Hughes-Hassell, 2006, p. 1419). boyd and colleagues (boyd, 2014; boyd and Marwick, 2011) have conducted considerable ethnographic research on American youth's online information practices, finding overall that young people's social practices online were natural extensions of youth culture that was previously enacted in offline spaces, to which young people's access has become increasingly restricted. Such findings are largely supported by additional research by Agosto and colleagues (Agosto et al., 2012; Agosto and Abbas, 2011).

Burek Pierce (2007) reviewed the literature on adolescent sexual and reproductive health information needs, finding that information seeking research on the topic is primarily being done by health researchers - sometimes with findings that are at odds with LIS theory and practice. Youth sexual health researchers outside of LIS are turning increasing attention to the role of the Internet in providing confidential information services to youth (Barman-Adhikari and Rice, 
2011; Gray et al., 2005; Hottes et al., 2012; Shoveller et al., 2012), but these studies rarely draw upon information behaviour theory or findings such as those by Agosto or boyd. As noted by Burek-Pierce (2007), such research has identified myriad gaps in access to sexual health information for youth, and suggests that increased information could alleviate related health inequities.

Information researchers have studied the everyday information seeking and practices of certain groups of adult parents, with a focus on mothers. McKenzie's extensive research on information seeking practices of twin mothers (McKenzie, 2006a), the midwife-client relationship (McKenzie, 2002, 2004, 2006b, 2009, 2010), and everyday life information practices of mothers (Carey et al., 2001; McKenzie, 2003), suggests that mothers engage in both active and passive information seeking practices, as well as exchanges of information between women and their maternity care providers. McKenzie developed a model of information practices based on her study of 19 adult women in Canada who were pregnant with twins (McKenzie, 2003). This model distinguishes among active information seeking, active scanning for information, non-directed monitoring for information, and seeking by proxy as different types of everyday information seeking, and identifies practices used for for connecting and interacting with information sources in the face of barriers.

Fisher and Landry explored peer information grounds - informal spaces for peer-to-peer information exchange (Fisher, 2005) — of older, affluent stay-at-home mothers, using a two-stage observation and interview approach. They found that affect (e.g., worry about their children) to be of great importance in shaping mothers' social information seeking and exchange (Fisher and Landry, 2007; Landry and Fisher, 2006). Loudon and colleagues (Loudon et al., 2016) drew on both Fisher's information grounds and McKenzie's information practices model in their 
investigation of mothers in the UK, using primarily observation and group interviews to explore their information needs, sources, and barriers to access. Many of the participant-identified information needs centred on child health and safety issues, and peer mothers were considered to be some of the most useful information sources consulted. Experiences with contested and conflicting information were sometimes emotionally fraught, and participants' fears over being judged to be a less-than-good mother shaped their information seeking.

Both Walker (2012) and Papen (2013) have qualitatively applied information literacy lenses to parental information practices. Walker used interviews in a constructivist grounded theory study to explore the information seeking, assessment, and use of British parents of schoolaged children, with findings that underscore both McKenzie's active and passive seeking practices and Fisher's information grounds. Walker's study also emphasizes the importance of trust in sources and information assessment for parents, and the stigma-related barriers that socially marginalized parents face due to their more limited networks and social capital. Papen's longitudinal qualitative investigation of highly-educated pregnant women's information practices in North England frames information literacy itself as a practice, finding that pregnant women grapple with competing and contested knowledge claims, often leading to assessment challenges despite high underlying literacy levels.

These studies, and particularly those centred on pregnant women or parents of babies, have tended to focus, either by design or by virtue of the data and themes that emerged therein, on health and health-related (e.g., baby feeding) topics, indicating that information related to health and well-being of new parents and their children is of high priority among these populations. This may be due in part to the fact that the above investigations into the information seeking behaviours and practices of mothers take place within contemporary western contexts 
dominated by what Hays (1996) named "intensive mothering” (sometimes expanded to “intensive parenting"). This is an ideology that places the onus on mothers (or in some cases parents of all genders/sexes) to seek and use authoritative and scientific information to mitigate risks to their children's safety and development (Lupton, 2014). Although commonly associated with middle class mothers (Afflerback et al., 2013; Fox, 2006), intensive mothering ideals are promoted and reinforced to marginalized mothers as well (Romagnoli and Wall, 2012). This underlying ideology, while rarely explicitly acknowledged in studies of parental information behaviours, undergirds the research questions, as well as findings, within contemporary western studies of maternal and parental information practices.

Several of the above studies of mothers' information seeking and practices conducted in LIS drew theoretically on Chatman's work, including her theory of information poverty (Chatman, 1996), a sociological theory that suggests a link between social marginalization, isolation, limited information access, and particular self-protective information-related practices including secrecy and deception as well as selective acceptance of new information. This theory was influential in Fisher and Landry's (2007) stay-at-home-mother study, and Walker's (2012) study of parents of school-aged children, despite none of those studies focusing specifically on marginalized populations of parents. While Walker found this theory particularly relevant for explaining the increased isolation of parents from relative lower socioeconomic backgrounds, Fisher and Landry applied Chatman's theories more broadly, finding that mothers of young children, often facing new experiences while severed from their previous peer groups and spending a great deal of time alone, seemed to occupy their own form of "small world" (Chatman, 1991). 
Loudon, Buchanan, and Ruthven (2016) identified young mothers, particularly those in their teen years, as an "understudied and potentially marginalised group" (p.24), recognizing the potential for social location to affect the everyday information seeking of a sub-population. Research on the health and well-being of young mothers and their children supports this idea, indicating that the interactions among maternal attributes, setting and contextual factors, and the treatment of the subpopulation of young mothers affects social experiences including but not limited to information needs and seeking. For example, the many randomized controlled studies of nurse information support to young first-time mothers using the "Nurse Family Partnership" model (Nurse Family Partnership, 2011) have indicated that the degree and nature of any improved outcomes in the group receiving intensive information support depends greatly on the "background" level of services and support for the comparator population, with greater intervention impact where underlying services were the poorest (see, for example, Hill et al., 2007; Mejdoubi et al., 2015; Robling et al., 2016). Additional observational research on young mothers' experiences with information-based services and programs (Romagnoli and Wall, 2012) indicate that participants have complex relationships with such programs, at once internalizing their norms as part of aiming to be "good" parents, and resisting them in efforts to push back against stigmatization of themselves as information needy. Based on such findings, it may be expected that the greater the degree of societal stigma and inequity, the more difference one might expect in information needs and practices between members of the majority and members of marginalized groups.

While the current study is the first known published investigation to focus specifically on the information practices of young parents, a marginalized group in contemporary Western societies, related literature can provide insight into themes that are likely important with this 
population. As adolescents, young parents are still working to complete adolescent developmental tasks, which may require information seeking to address personal growth needs. Youth culture has shifted in urban North America to take place increasingly in social online spaces, and privacy and confidentiality are challenges to negotiate, particularly in regard to topics such as sexual and reproductive health. Mothers — and perhaps also fathers — appear to frequently engage in health-related information seeking, both actively and passively, and social information exchange among peers likely holds great value for new mothers in particular. The ideology of intensive mothering places onus on mothers to seek and integrate information into their parenting, yet socially marginalized parents may lack access to information or deliberately engage in protective information practices that limit their information sharing and use.

\section{Research Question and Study Objectives}

The overarching research question guiding this study is: What are the health-related information practices of young parents in Greater Vancouver? The current study explores the health-related information practices of a sample of young parents in order to:

1) Describe the ways in which these young parents engage in health-related everyday life information practices such as seeking, use, and sharing;

2) Identify how those health-related information practices connect with, contradict, or relate to each other; and

3) Examine the ways in which these information practices potentially inform health decisions and behaviour.

\section{Methods}

This longitudinal, qualitative study used constructivist grounded theory (Charmaz, 2007, 2009) to investigate the health-related, socially constructed information practices (McKenzie, 2003; 
Savolainen, 2008) of young parents over a span of 16 months. This analysis was part of a larger doctoral dissertation (CITATION BLINDED FOR REVIEW), which in turn nests within an ongoing, interdisciplinary, longitudinal, multi-site study of social context and the experiences of young parents.

\section{Theoretical Orientation}

Information behaviour is currently the dominant umbrella term "used to describe the many ways in which human beings interact with information, in particular, the ways in which people seek and utilize information" (Bates, 2010, sec. 1.1). Over the past three decades in information behaviour research there has been a shift away from a focus on systems for information seeking toward a focus on the humans who use (or do not use) such systems, and the contexts in which humans carry out information-related activities (Case, 2006; Talja and Hartel, 2007; Wilson, 1999). Many contemporary information behavioural scholars draw on behavioural research in the social sciences to study people's information needs, as well as how they seek, avoid, access, assess, and use various types of information. For example, Dervin (1992; Dervin and Nilan, 1986) adapted the social scientific concept of sense-making to apply to the process of an information user's cognitive (and in some interpretations affective and social) negotiation of information for use in a "real life" context.

Savolainen (2007, 2008; Wilson and Savolainen, 2009), along with a growing cadre of information behaviour researchers (Fry, 2006; Johannisson and Sundin, 2007; McKenzie, 2003; Talja and Hartel, 2007), eschews the term "information behaviour" because the term itself is awkward (strictly speaking, information does not behave), and because it may carry overtones of a dated and limited positivist, or behaviourist, worldview. Drawing on the turn to practice within social sciences more broadly (Bourdieu, 1977, 1998; Camic et al., 2011; Fraser, 1990; Reckwitz, 
2002), these scholars adopt a practices approach. Such an approach shifts the focus away from cognitive models in which information needs trigger seeking and subsequent use, and onto the socially-constructed ways that people "do things" with information (Talja and McKenzie, 2007, p. 100): information practices. Savolainen $(2007,2008)$ asserts that while the concepts of information behaviour and information practice may appear similar, the ontological and epistemological differences in the two perspectives position them differently. In practice, the use of the term information behaviour has become so prevalent that it is used for investigations and theories from multiple perspectives; information practices, however, has more recently been adopted by researchers seeking a deliberately social constructionist alternative framing for the broad concept of people doing things with information.

A major focus within information practices research is "everyday life" information seeking (ELIS) (Savolainen, 1995, 2005, 2009). ELIS investigates information practices (with emphasis on seeking) of people engaged in activities that are part of their personal lives, as distinct from professional, school-related, or work-related information seeking. The shift of focus of some researchers to ELIS marked a departure from previous research that focused primarily on work roles and academic tasks, to more of a sociology of information practices in daily life. The current study situates itself within this tradition of ELIS and everyday information practices, drawing heavily on Savolainen's social phenomenological methods and model in the study design. Accordingly, the language used within this study is that of practices; however when other research is discussed, the language of behaviour is used if the study did not take a practices approach.

The practices approach, which acknowledges the power of social structures in shaping people's activities and routines, lends itself well to investigations of health that take a population 
health approach. Population health, often framed as a subset or evolution of public health (Hawe et al., 2012; Kindig and Stoddart, 2003), emphasizes social determinants of health (Marmot and Wilkinson, 2005; Raphael, 2009) - those underlying social and structural factors that shape the well-being of populations, for example education, housing, food security, and racial and gender discrimination. A population health approach defines health broadly, including but not limited to medical conditions and outcomes, aiming to reduce health inequities among and within population groups, as well as to improve the well-being of the population as a whole. This study focuses on everyday life health information practices of a young parent population, defining health-related information broadly to include topics such as housing, education and career development, income security, child development, and emotional well-being, as well as information related to specific medical conditions.

\section{Study setting}

This study took place in the Greater Vancouver metropolitan region of British Columbia, Canada. Within Greater Vancouver there is a patchwork of programs and services aimed at supporting young parents and their children. Key among these are Young Parent Programs (YPPs), a network of school-based, community-partnered, provincially-supported programs for young parents completing secondary education. Nearly every city in Greater Vancouver hosts a YPP, which serves as a hub for collaborative programming among schools, non-profit societies, childcare providers, and public health outreach.

\section{Data collection}

Data was collected via ethnographic observation and individual interviews from October 2013 to December 2014. The majority of the observation and interview participant recruitment took place at two school-based YPPs. During observations, the researcher was present in the classrooms and 
took notes or participated in activities as appropriate at the time, including out-trips (e.g., to exercise classes, community centres) as scheduling permitted. Commonly-observed activities at the YPPs included classroom lessons (e.g., English, social studies, math), parenting classes, arts and crafts, food preparation and lunchtime, and presentations from guest speakers representing social services and public health organizations.

Interview participants were initially purposively recruited from the student populations of the two YPP observation sites, by providing information about the study to young parent students, and offering to arrange individual interviews either on-site or elsewhere in the community. Interview participants were given a $\$ 30$ cash honorarium per interview. Eligible participants were required to be at least 15 years old and less than 25 years old, and either expecting a child or parenting one or more child(ren). As the study progressed, both purposive and theoretical sampling were used to guide recruitment of additional participants from the YPPs and via service provider word of mouth, as well as from other local community organizations that served young parents: neighbourhood houses ${ }^{2}$, a postsecondary education institution, and a non-profit serving street-involved youth.

Semi-structured interviews followed a predetermined interview guide that included questions on a range of topics spanning medical issues as well as social determinants of health such as housing, childcare and parenting, income, and social relationships, in order to understand the participants' social contexts, current goals and challenges, and personal histories. To investigate and triangulate participants' health information practices three different elicitation methods were used in the intake interviews: 1) open-ended questions probed participant information seeking, avoidance, encountering, use, and sharing; 2) information world mapping (Greyson, 2013), an arts-based activity, asked interviewees to draw their personal health 
information worlds and then discuss these maps; and 3) critical incident technique (Flanagan, 1954), a verbal storytelling method that has been successfully used in for many years in both health (Kemppainen, 2000) and information research (Urquhart et al., 2003), was used to elicit specific examples of health information seeking, sharing, or use, and relate these back to a participant's information world maps and responses about their general health information practices. Participants who conducted their intake interview in the first or second of three fieldwork rounds were invited to participate in one or two follow-up interviews. Follow-up interviews were spaced approximately four months apart, in order to prospectively follow participants' evolving lives and practices, as well as to test emerging theories.

\section{Data analysis}

Interview transcripts and typed field notes ${ }^{3}$, along with photographs of information artifacts (information world maps and information materials in the YPP environment), were imported into NVivo 10 Software (QSR International) for coding via the constant comparative method of systematic coding and analysis across data sources (Glaser, 1965; Glaser and Strauss, 1967). This analysis was guided by Charmaz' (2007) constructivist grounded theory. In keeping with traditional grounded theory methods, data collection and analysis were not discrete stages, but rather they were overlapping and iterative processes (Charmaz, 2007). Visual artifacts were used to augment the coding of field notes and interview transcripts, but not coded themselves. Initial open coding to develop tentative codes led to extensive memo writing and an iterative process of constructing focused codes around the study objectives, diagramming emergent theory, and selective coding in order to surface stories of theoretical significance to the emergent theory and study themes. 


\section{Ethics}

Written informed consent was obtained from each interviewee at each interview. Transcripts used participant pseudonyms, and removed potentially-identifying information such as other names, dates, and specific locations. Interviewees were provided with the opportunity to member-check (review) their transcripts to correct errors or request additional anonymization. Written informed consent was also sought from students and staff present during observations, without which no quotes from or details regarding a non-consenting individual were recorded. This study was approved by the Behavioural Ethics Review Board of the [UNIVERSITY BLINDED FOR REVIEW] (H13-00415), and given research approval by the school boards of both participating YPPs.

\section{Results}

The data for this analysis includes 50 days of naturalistic observation and 60 individual interviews: 39 intake interviews, 18 second interviews, and three third interviews, for approximately 69 hours of total interview time.

\section{Participants}

The study population was diverse in many ways. While the two participating YPPs had an upper age limit of 19, subsequent theoretical sampling via community recruitment resulted in participants aged 20-23 years as well. Within the entire sample the mean age at time of intake interview was $18.3(\mathrm{SD}=2)$, the median age was 18 , and the mode was 17 (see Figure 1 ). 


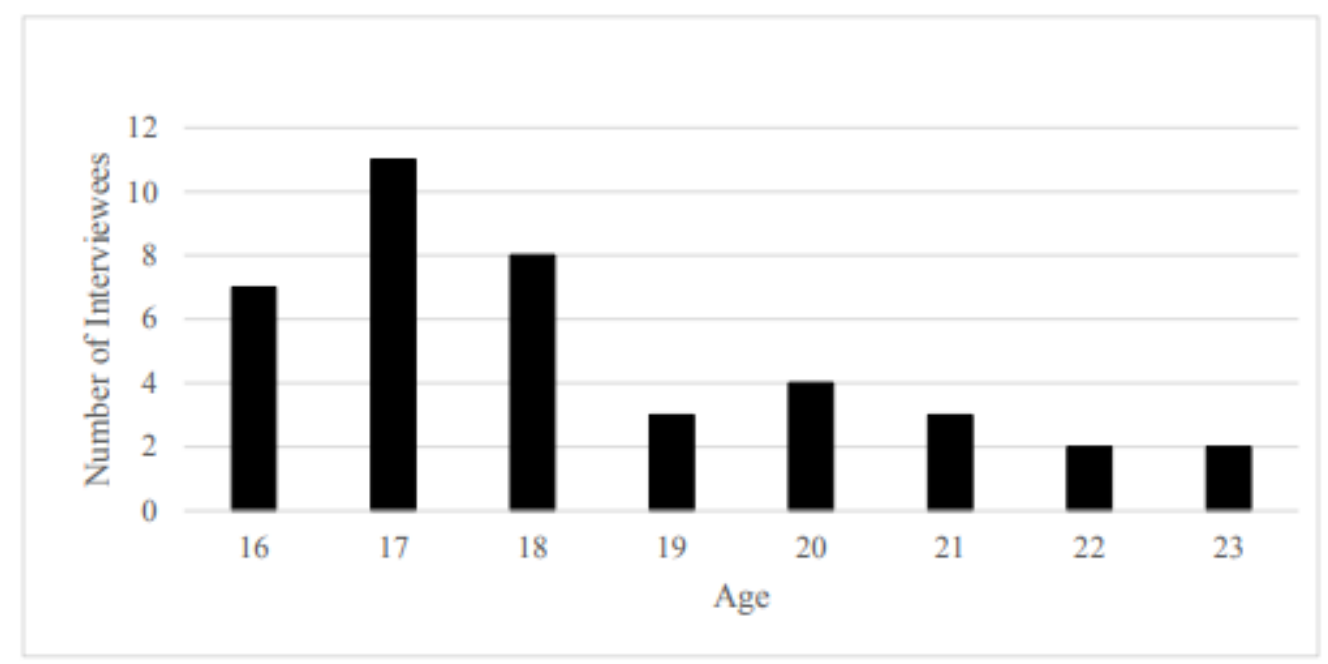

Figure 1. Interview Participant Ages

The sample comprised 37 mothers (one of whom also identified as gender non-binary) and two fathers. Most interviewees $(n=36)$, including both fathers, identified as straight; however there were a minority who self-identified as bisexual or pansexual, or as unsure or questioning. In cases where participants' sexual orientation shifted during the course of the study, both identities are presented in Table 1 . The majority $(n=28)$ of the 39 interview participants were currently working on secondary school diplomas, either through high school $(n=26)$ or adult education $(n=2)$. The sole participant who had completed a postsecondary program was an immigrant who had completed schooling abroad at an earlier age than would be typical in Canada. 
Table 1. Interviewee Demographic Characteristics

\begin{tabular}{lrr}
\hline $\begin{array}{l}\text { Gender Identity * \# of } \\
\text { Participants }\end{array}$ & & \%** \\
\hline Woman & 37 & $95 \%$ \\
Man & 2 & $5 \%$ \\
Transgender & 0 & $0 \%$ \\
Something else & 1 & $3 \%$ \\
\hline Sexual Orientation* & & \\
\hline Straight & 36 & $92 \%$ \\
Lesbian/Gay & 0 & $0 \%$ \\
Bisexual/Pansexual & 3 & $8 \%$ \\
Questioning/Unsure & 2 & $5 \%$ \\
\hline Education Level at Intake & & \\
\hline Incomplete secondary & 3 & $8 \%$ \\
Secondary in progress & 27 & $69 \%$ \\
Completed secondary & 4 & $10 \%$ \\
Currently in college/university & 2 & $5 \%$ \\
Completed college/university & 1 & $3 \%$ \\
Completed postsecondary trade program & 1 & $3 \%$ \\
Other postsecondary certificate & 1 & $3 \%$ \\
\hline Immigration Status & & \\
\hline Self: Born in Canada & 32 & $82 \%$ \\
Self: Born Elsewhere & 7 & $18 \%$ \\
Parents: Both parents born in Canada & 23 & $59 \%$ \\
Parents: One parent born elsewhere & 7 & $18 \%$ \\
Parents: Both parents born elsewhere & 9 & $23 \%$ \\
\hline Categories not & &
\end{tabular}

* Categories not mutually exclusive

**Rounded to nearest $1 \%$

Interview participants had a variety of cultural and ethnic backgrounds. While most $(n=$ 32) were born in Canada, the seven born elsewhere hailed from six different countries, representing five continents. In addition to those seven, nine additional participants (for a total of 16) had one or more parent born abroad. Figure 2 illustrates the self-selected ethnic identifications of participants. Ethnicity categories were not mutually exclusive, and 11 participants identified with multiple categories; in Figure 2 the dark portions of the bars indicate 
participants who identified solely with an ethnicity category and the lighter shaded portions of bars represent those who selected that category plus one or more others. Within the study sample, most participants identified as Caucasian, Latin American, and/or Indigenous (inclusive of First Nations, Metis, Inuit, and non-status Aboriginal Canadian, as well as Indigenous populations from other parts of the world).

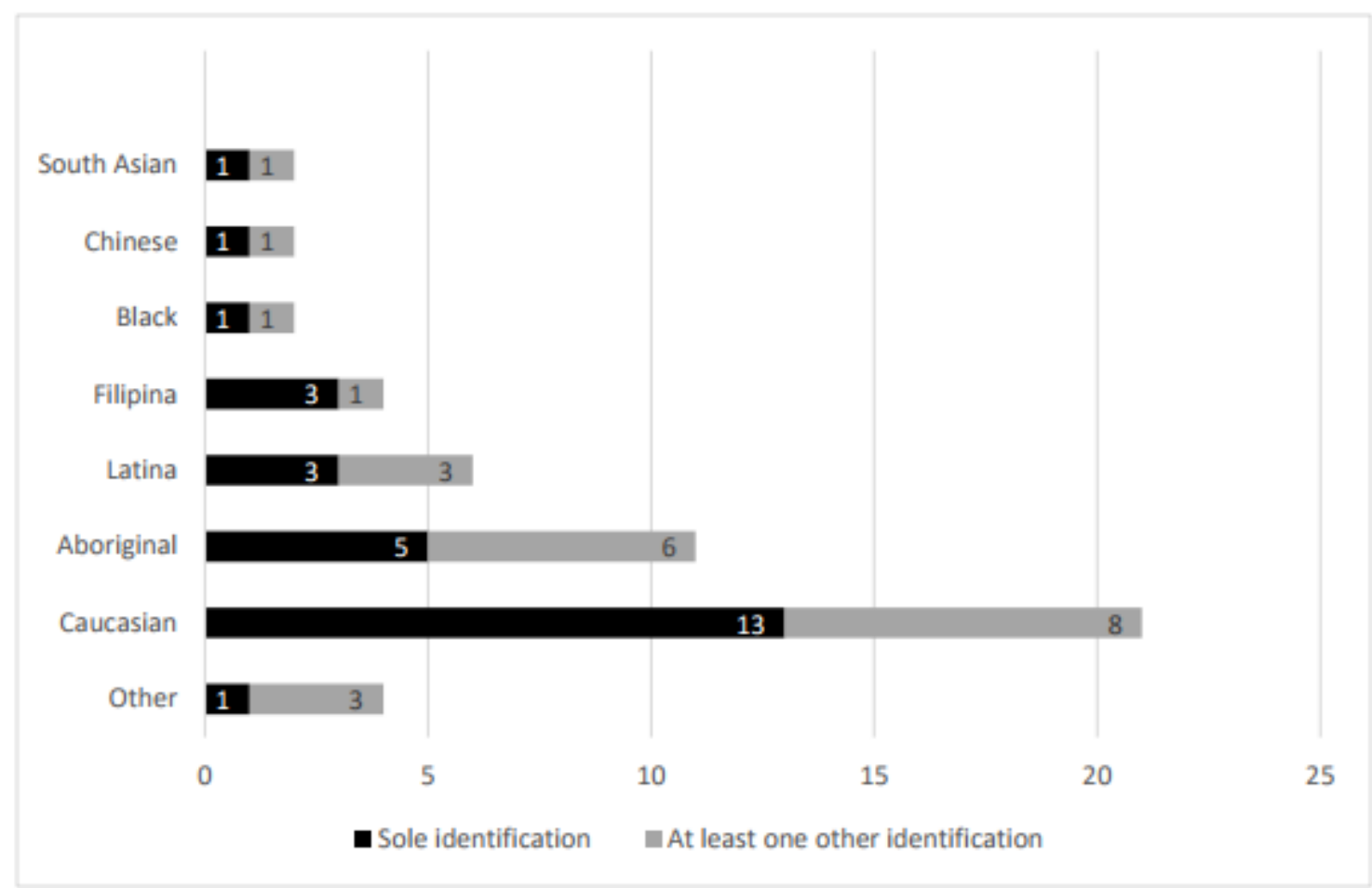

Figure 2. Interviewee Self-Identified Ethnicity

Most of the interview participants $(n=28)$, including both fathers, had one child at the time of intake interview (see Table 2). Three mothers had two children; one of these was parenting one step-child and one to whom she had given birth. In addition to the eight mothers expecting their first baby, two were expecting their second, and one was unsure whether or not she was pregnant again. Over half of the participants $(n=26)$ had never experienced a pregnancy that was not 
carried to term, but 13 mothers did disclose previous therapeutic abortion $(n=8)$, and/or miscarriage $(n=6)$.

Table 2. Participant Reproductive Histories at Intake

\begin{tabular}{lcc}
\hline Lifetime Pregnancies & \# of Participants & $\%^{*}$ \\
\hline One & 25 & $64 \%$ \\
Two & 10 & $26 \%$ \\
Three & 4 & $10 \%$ \\
\hline Births & \\
\hline Zero (currently expecting) & 8 & $21 \%$ \\
One & 28 & $72 \%$ \\
Two & 3 & $8 \%$ \\
\hline Pregnancies not carried to term & & \\
\hline Zero & 26 & $67 \%$ \\
One & 12 & $31 \%$ \\
Two & 1 & $3 \%$ \\
\hline
\end{tabular}

* Rounded to nearest $1 \%$

\section{Health information practices of young parents}

The semi-structured interview guide that shaped data collection was built around Savolainen's (2008, p. 49) conceptual framework of major components of everyday information practices, which classifies such practices into three groups: seeking (inclusive of source identification and information acquisition), use (inclusive of value assessment, extraction of meaning, and application of information to action), and sharing (with others).

However, in this inductive analysis aiming to co-create with young parents an understanding of their health-related information practices, practices clustered slightly differently. Information management practices emerged as an important, often time and energy consuming, set of practices that involved a great deal of assessment work. Assessment tasks were not conceptualized as part of use, but rather a prerequisite for use (e.g, informing action). 
Additionally, sharing within this context was considered a type of use, as mediating information for others was a common practice that both fulfilled social roles and built social capital for many study participants. Therefore, in this analysis, health-related information practices of young parents are clustered into groupings of: (1) ways of getting and not getting health information (the "seeking" cluster of practices); (2) ways of dealing with health information ("assessment" cluster); and (3) ways of using health information ("use" cluster). The results below are presented accordingly.

Seeking, encountering, and avoiding. In this analysis, seeking refers to "purposive seeking for information as a consequence of a need" (Wilson, 2000, p. 49). Seeking is therefore distinct from needs (not a practice) and use. Seeking is an active practice, as opposed to unintentional encountering, seeking's more opportunistic counterpart. Within this practice cluster that is focused on ways of obtaining information avoidance is also included (Case et al., 2005) as the antithesis of seeking and encountering.

Seeking. Young parents sought health information from people and institutions, as well as online and from print materials. Some questions led to only one source while others were multimodal and iterative. Participants described both proactive and reactive strategies for seeking health information for themselves and others, as well as factors that hindered or inhibited information seeking. Topics about which young parents sought health information ran the gamut from common pregnancy questions (e.g., is this safe to eat?) to immediate child health crises (e.g., is this rash a sign of a serious illness?) to ongoing health concerns (e.g., does my child have ADHD?).

Information needs related to child health emergencies were consistently responded to by seeking formally authoritative medical information (e.g., from doctors, hospitals). However, for 
less urgent needs, strategies and sources varied. Young parents often consulted human sources with whom they had close ties and affinity (e.g., their own mothers). However, some placed value in an ethic of self-sufficiency, preferring to avoid asking family and friends for help.

In contemporary urban Canadian youth culture, smartphones are ubiquitous and free access to the Internet is only as distant as the nearest café. Therefore, the information seeking method of least effort and greatest immediacy was frequently an Internet search. Although there were notable Internet non-users within the sample, this was rare. Most young parents reported regular online seeking, both for convenience and because - unlike human sources (the classic "least effort" (Zipf, 1949) source type)—search engines would not disrespect a seeker for being young (or Indigenous, an immigrant, etc.).

Young father Victor, the oldest interview participant at 23 years of age, and one of the few library users in the study cohort, described an array of health information seeking techniques in which he engaged, differentiating between proactive and reactive practices.

[T]he library, community centres, are a pro-active kind of [information seeking]. You know, preparing ourselves for things....[The] help line is more like we [had a] need for something at that second[...]you know, nobody's there to ask a question late at night, right?

Victor included family and friends as information sources that could be consulted in both a proactive ("what to expect") and reactive ("what to do") manner. Classifying sources as appropriate for proactive or reactive seeking was common, crossing lines of gender/sex, ethnicity, hometown, and age. Unlike Victor, however, many of the mothers described a substantial amount of proactive seeking online on social media or parenting websites. 
A rare but notable subset of proactive information seeking that surfaced in the interviews was defensive information seeking - engaging in seeking in order to demonstrate being an educated parent. Young mother Ella, a 17 year old whose family of origin had substantial involvement with child protective services, reported attending several parenting classes while pregnant because she had been warned that the authorities might try to take her baby away. Clearly accustomed to using information to advocate for herself, Ella brought a folder of paperwork to her intake interview. While describing this defensive form of information seeking, she spontaneously produced documentation of different classes she had taken as evidence, explaining:

I did parenting skill development, relationship counseling, so that me and [partner] wouldn't argue in front of her. "Baby's Best Chance"-I did that for really, like, almost a year and a half. "Aboriginal Infant Development," [also.] While Ella acknowledged that some information from these classes had been useful, her motivation and primary objective in this intensive information seeking via formal classes was to defend her family by demonstrating her commitment to seeking and mastering parenting skills and knowledge that had been approved by an officially authoritative source.

In some instances, participants sought information without asking questions. Two forms of this passive or subversive information seeking were complaining and sharing "TMI" (short for "too much information"-i.e., sharing of personal, often taboo information such as regarding sex or menstruation). Young parents managed "asking without asking" about a taboo topic by sharing TMI, for instance in this YPP classroom scenario:

Staff member "Cookie" mentions that she was out earlier in the week due to a medical issue. Student "Crystal," who is making herself coffee, chimes in that 
she has to go to the gynecologist because she's been bleeding for several months and they can't figure out why.

Following Crystal's announcement, Cookie went over to see if she could provide information and support. Although Crystal wasn't explicitly asking for help or advice, and in fact made her declaration with an air of bravado, in her subsequent interview she revealed that she was worried about the excessive bleeding and related anemia. In this case, revealing personal health information that could be judged to be TMI served as a masked information seeking technique.

Complaining functioned in a similar manner. Eighteen year old young mother Kagome demonstrated this technique by complaining loudly about issues in her life such as her toddler hitting other children or a male friend making unwanted sexual advances. Although she did not explicitly ask for advice navigating these challenging scenarios, YPP staff rose to the occasion, with clarifying questions, information, and emotional support. Within the context of the YPPs, this subversive information seeking occurred in liminal times, such as before class officially began or during lunch. While the YPPs are organized so as to provide formal spaces for information exchange, it was these informal and temporary "grounds" that made space for information seeking and exchange around topics that might be taboo or shameful to formally raise in the classroom setting.

While young parents applied many seeking techniques with ease-a nearly effortless Internet search or call to the nurse line by a native English-speaker, for example-in other cases seeking was quite challenging. Individual skill-based challenges took various forms, including limits on English literacy, health literacy, and information literacy. Socio-emotional challenges, such as worry over a possible negative diagnosis, were reported as hindering health information seeking, even when not leading to complete information avoidance. A related challenge was the 
culturally-based nature of available information on healthy pregnancy and parenting. Advice of formal experts at times directly contradicted with social practices among a young parent's own family or culture. While young parents in this study navigated this tension in multiple ways, in some cases the awareness that cultural and "scientific" norms deviated discouraged information seeking.

Encountering. Describing information encountering did not come easily to all interviewees. In some cases, interactions that might appear to be incidental encountering were perceived by interviewees as active seeking or scanning_-for example reading public health advertisements on public transit. Participants' encountering stories typically centred on unsolicited comments containing prenatal and parenting advice. Sometimes such encounters were positive in tone, but the more instructional ones tended to be perceived as judgemental or intrusive. These encounters, reported by mothers and fathers alike, frequently took place in parks and on public transit. Eighteen year old young father Saul described an experience that typified this type of information encounter: "[Y] ou know, someone comes up and says, 'She's not supposed to be drinking [juice],' or something." Participants often reported feeling put on the defensive by such information, especially coming from strangers. Saul continued the above story, providing context and evidence to justify the decision to give his daughter juice:

You know, lots of people raise their children differently. Like, if [my daughter] wants juice, I'll give her some juice but I'll give her half a juice and fill the rest with water or, you know, something like that. Most parents do that. My mom did it.

On social media, unsolicited health advice could be encountered in a way that was perceived to be less aggressively targeted, however. While comments posted to a young parent's 
page or timeline were potentially intrusive (similar to in-person comments), online acquaintances broadcasting of health information to a curated list of followers or "friends" occupied a middle ground between general public health information campaigns, which were often perceived as boring and impersonal, and individually tailored comments, which were sometimes seen as nosy and invasive.

Avoiding. Not all participants were aware of avoiding health information. However, among those who did describe avoidance practices, there were clear groupings of avoidance types. The first of these was avoidance of information related to issues or events that were frightening to the individual. These were topics such as an upcoming childbirth, which were inevitable but culturally constructed to be frightening. Nineteen year old young mother Kim was generally highly engaged in information seeking. However, she described avoiding information related to possible fetal harms due to "partying" before she realised she was pregnant. Given that Kim could change nothing about past actions, she explained:

I just didn't want to deal with all of the issues of being pregnant and knowing you were drinking at your grad ceremony. I was just like, "This baby has survived this long, I'm not gonna get worried about how many kicks is she doing a day or that kind of thing."

A second, related, type of avoidance was avoiding information so as not to invite trouble or cause unnecessary worry. Multiple young parents who took a "relaxed" approach to parenting echoed this idea of the perils of too much information. This relaxed approach or type of avoidance did not correspond to education level, ethnicity, or quantity of active information seeking among participants. However, those who described avoiding information so as to minimize excessive worry frequently also engaged in a "natural" parenting discourse. Examples 
of this natural discourse include referring to a maternal instinct that would alert one to real danger, and considering it healthier to bear children in one's teens or twenties than to delay childbearing until one's forties when the odds of needing medical intervention were greater.

A number of interviewees described avoiding information from sources they had assessed to be disreputable. This practice demonstrates the iterative connections between practices of seeking/avoidance and assessment of obtained information. Dismissal of "disreputable" sources was also observed at YPPs, although the teacher-student dynamic added a layer of complexity to assessments of authority. Crystal, a 17 year old young mother, described a difficult process of deciding whether or not to vaccinate her infant. Once she had decided to vaccinate, she reported that she "stopped listening to" all health advice from those parties that had been advising nonvaccination.

A final type of health information avoidance that was described by only a few interviewees was that of avoiding information because they had been "too young" at the time to take things seriously or plan for the future. This is a complex type of avoidance, particularly because it was narrated only by young mothers with preschool children describing retrospectively how they had behaved three to five years earlier. Twenty-two year old young mother Elena described avoiding childbirth education during her first pregnancy, "I was too young to actually think... about what it—like, I just—I didn't think about it."

Given how much time had passed since the examples of these "too young" types of avoidance, it is difficult to interpret whether they are actually a subset of avoidance of frightening information, or whether they are indeed a distinct type of avoidance practices. It could be that this discourse of being "too young" to seek or engage with information is referencing an early adolescent developmental stage, although the ages at which this avoidance is 
described are inconsistent. It seems likely that being "too young" refers not to age or stage, but to a lack of agency - a feeling that life is happening to them, and is something over which they have little control. However, the retrospective narration across time also implies that the narrator is now, years later, older, wise, and different: more agentic, or more capable of engaging in practices of educated, information-using motherhood.

Assessing, storing, and discarding. Information assessment emerged as a major task for young parents, and therefore comprises a significant set of health information practices. Assessment served a gatekeeping function, creating a demarcation between information acquisition and use (or non-use). Judgements of relevance, credibility, and various constructs of authority were all evident within the assessment of information conducted by young parents.

Assessing. Assessment of health information for "goodness" (a combination of attributes unpacked below) was ubiquitous among young parent interviewees. However, assessment of information, particularly online information, posed challenges. Some challenges were skill-based, such as lack of knowledge and confidence regarding how to filter and evaluate information, resolve contradictions among information sources, or apply given information to one's individual situation. Other challenges were socio-emotional, for example feeling overwhelmed by negative information, pressured to make a health decision quickly, or stressed because an important decision had to be made alone.

Assessment challenges in context frequently involved both skill-based challenges and socio-emotional challenges. For example, during a lesson at a YPP on proper formula bottle preparation for infants, one student challenged the information being provided, protesting that conflicts between it, the instructions from her doctor, and her family's cultural practices, left her confused. Throughout this presentation, staff referred to chronic health issues of this particular 
student's baby, implying that she was the underlying reason for the lesson. By the end of the presentation, it was clear that the student was unconvinced of the correctness of the information presented, left with an unresolved conflict of information among multiple information sources with different types of authority, and now upset by the implication that she might have been causing her baby's symptoms.

While the vast majority of the young parents in this urban cohort had easy access to the Internet for frequent information seeking, access did not equate to ability to accurately assess online information. Common methods for deciding what online information to trust included relying on the most familiar sites or following top-listed search engine results. Factual accuracy, however, was just one element of information "goodness." Health information was assessed on attributes including relevance, credibility and source. Good health information was described as accurate and trustworthy, but also timely, individualized, and non-judgemental in nature.

Participants also had criteria for assessing information as bad, including inaccuracy, originating from an untrustworthy source, or being unrealistic for one's situation. Interviewees provided many examples of potentially-accurate information that was nevertheless not useful for them, because to apply that information would have been culturally taboo or otherwise unacceptable in the context of a young parent's life. An important criterion was fit for one's current socio-emotional and developmental state. Otherwise "good" information could become bad if either the timing was wrong or the information was alienating to a given young parent. Eighteen year old young mother Linda identified the information she received in childbirth education classes as poor. However, she acknowledged that this may have been because she was fatigued and unable to be an attentive member of the class, which was not being taught in her native language. Other reasons information was assessed by young parents to be bad included 
over-reliance on scare tactics and negativity, being too boring, or having an overly paternalistic tone.

Assessment of a given piece of information was affected by the cognitive authority (Rieh, 2009; Wilson, 1983) ascribed to its source. Cognitive authorities' information is "taken more seriously" (Rieh, 2009, p. 1340) than other information, and study participants recognized multiple bases for such authority. Sources identified as "officially" authoritative in matters of health information included government sources and health care professionals. Twenty-one year old young mother Bina, who had been a nurse in her home country prior to immigrating to Canada, placed high cognitive authority in doctors, consulting them as "the smartest place" for health information. However, many other young parents ascribed a great deal of cognitive authority to sources they found to be "relatable," regardless of whether those sources were officially authoritative.

Relatable meant different things to different people, but tended to have to do with shared experiences, gender, and culture. Young mothers often felt that their own mothers' health information was relatable, and some also classified advice from their young parent friends as such. However, this criterion of the relatability of information extended beyond the social circle. Seventeen year old young mother Kristey, for example, did not feel that her male doctor's information was very useful, because his gender prevented him from being relatable. She explained, "I think lady doctors give more good advice than guys. Or other pregnant women [also give good advice]." Ella specifically identified relatability as an attribute of a good information source, telling the following story about her social worker:

[M]y social worker, she doesn't have any kids, she doesn't have any responsibilities. She told me she can go home, lay on the couch, and drink a 
scotch and she wouldn't have anything to worry about till Monday. And I

thought that was such a big slap in the face.

In Ella's story, the social worker lacked cognitive authority due to her lack of relatability. She was unrelatable for multiple reasons: first because as a non-parent, she lacked firsthand knowledge of parenting responsibilities, and second due to the cavalier manner in which she spoke about alcohol use, which had been a scourge for Ella's family and Indigenous community. As a result, even if information from this source met all other criteria for information goodnessaccuracy of content, acceptability and usefulness, and appropriate tone, content, and timingElla was unlikely to perceive it to be trustworthy.

Storing and discarding. Storing and discarding information occurred as a result of assessment, but sometimes after only the most perfunctory of assessments. Some young parents had no system for managing or storing health information, seeking information only on an asneeded basis. Others had developed methods of retaining health information they thought might come in handy at a later time. Despite general disdain within the study population for pamphlets and brochures, several participants described storage systems such as folders or drawers for such materials. For example seventeen year old young mother Sarah, who found pamphlets to be "boring," explained, "I have like, a whole file folder and I just put them all in there. I don't really throw them out. I just collect, I'd say.” When probed regarding why she kept them, she responded, "I dunno; I just kinda keep them. Maybe when I'm bored I'll look at them. But I won't ever, really." A number of the young mothers in particular retained print materials even though they never expected to use them, a practice less indicative of storage for future use and more akin to the aforementioned defensive information seeking practices. By storing child health 
information, young mothers engaged in a social practice indicative of intensive mothering, thus using information to demonstrate from a socially marginalized position their fitness as mothers.

Discarding, the opposite of storing, was rarely discussed in depth. While it was not uncommon for young parent interviewees to mention non-use of information, the actual act of discarding materials seemed non-noteworthy. Throwing out, recycling, or deleting information artifacts was only acknowledged when specifically probed; otherwise, participants typically focused on non-use or active ignoring of information rather than de-acquisition. At the YPP sites health-related information ephemera such as brochures often lingered for a long time in locations such as on student desks and front-of-classroom tables. This may indicate that while such information artifacts may not be perceived as useful, there remains a reluctance to actively discard them, whether out of a desire to retain such materials in the environment "just in case" or a desire not to be perceived as an information discarder (and thus failing to conform to ideals of intensive motherhood).

Use: Information sharing and informing action. Sharing, in organized settings for information exchange, informal social information grounds (Fisher and Naumer, 2006), and within individual interactions, was one of the main ways young parents described using health information. Conversely, young parents reported specific instances of deliberately hiding or selectively withholding information. A subset of sharing information was acting as lay information mediaries (Abrahamson et al., 2008; Abrahamson and Fisher, 2007) for others in young parents' social networks. The second major way young parents used health information (and, at times, misinformation) was to inform health decisions, actions, and behaviours.

Sharing. Young parent services, including new mother drop-in groups and health and community facilities, frequently provided spaces in which information sharing was intended to 
take place. At the YPP sites young parents shared health information with peers and staff both formally and informally. Structured information sharing activities tended to focus on topics of public health priority, such as baby feeding and contraception. In more informal conversations a wide variety of topics was covered, ranging from recipes to affordable housing leads.

Non-youth-specific parent spaces also had the potential to become ad hoc grounds for information exchange. For example the baby section within a store, where mothers might casually offer each other product advice. However, some young mothers reported feeling alienated and excluded by older parents in such places. Kim, for example, perceived that her contributions at a community centre drop-in group were dismissed due to her age, and eventually modified her information seeking and sharing practices to only include young parent groups. Twenty year old young mother Brooklynn avoided non-youth-focused parenting groups altogether, based on the experiences of a young mother friend of hers.

[S]he went a couple times and every time she went that she just felt really singled out. None of the older parents really wanted to talk to her and they were kind of just wondering, "What is this kid doing here? Is she like, the babysitter or something?"

Social stigma, therefore, emerged as a modifying factor in young parents' health information sharing practices and options for accessing information grounds.

Sharing also took the form of being an information intermediary for others, such as a partner, family member, or even service provider. Young parents described mediating information for others in two different ways: passing along information they already had, or seeking out, assessing, and then sharing information specifically obtained for that person/purpose. The former type of mediation occurred regularly and casually among young parents, as well as 
from young parents to service providers, who were sometimes less aware of local services than the parents themselves. Designated information seeking and mediation appeared less common, with the exception of seeking information for one's child, but did occur. For example, 21 year old young mother Darkat had a violent boyfriend, and described her process of searching online to find the contact information for a program for male abusers, calling to assess their information, and finally sharing the information with her boyfriend in hopes that he would use it.

There were also times and situations in which young parents attempted to hide or otherwise not share health information. Many examples of information non-disclosure centred on stigmatized information such as drug use during pregnancy, abortions, and childhood abuse experiences. However, another group of non-disclosure practices emerged around information that would potentially cause or change government intervention, for example a young mother hiding the fact that her boyfriend lived with her in subsidized housing.

Informing health decisions and behaviour. In certain situations, young parents engaged in a great deal of deliberate, even formalized research, in order to inform a health decision. Kim, the only in this cohort to have planned to place her child for adoption, engaged in an intensive information seeking and use process that ultimately led to the decision to raise her child herself. She described going over her memories and the memorabilia of her childhood, talking with her mother about what it was like to raise a child, reading the questions and answers on a parenting website, and then engaging in a process of integrating and considering those multiple sources of information to decide whether she could cope with parenting.

In contrast with Kim's in-depth information integration process, several young parents reported rapid application of information to health behaviour. The most common example of this was confirmation of a pregnancy, which carried implications that interviewees - particularly 
young mothers - took seriously. Regardless of whether the pregnancy was planned, hoped-for, serendipitous, or unwanted, confirmation frequently led young mothers to make rapid changes in their health behaviours. Many described cessation of drugs and alcohol when they found out they were pregnant, and others described changes to exercise, diet, and other health behaviours. After childbirth, there were myriad examples of young mothers and fathers alike using information to inform health decisions for their child and family. Saul reported that he and his partner were using a budgeting booklet to try to eat cheaper, healthier food. Victor's dad gave him parenting tips via Skype that he tried to follow.

Misinformation also informed health behaviour. Kristey, for example, described weaning her infant at an early age because she was unable to quit smoking.

I quit smoking for two weeks after I had her because I didn't want it to go in my breast milk and I heard everything goes through your milk. And... I started again, but I never breastfed her [after that]. I just put her on formula because I was too scared to give her nicotine through breast milk.

Informed by public health campaigns that emphasized the importance of breastfeeding for infant health, Kristey stopped smoking for two weeks postpartum, but then relapsed and switched to formula over fears regarding passing nicotine to her baby via breast milk. In addition to potential health impacts for mother and baby, formula feeding is expensive, and this switch was likely a substantial expense to Kristey's family.

Kristey's switch to formula feeding is an example of a specific type of misinformation: that arising from public health scare tactics (anti-smoking messages) conflicting with other public health messages (pro-breastfeeding). Kagome told of a similar situation, in which she had switched from coffee to sugary and artificially-coloured Slurpees in order avoid caffeine while 
pregnant. For an individual trying to make informed decisions within a climate of conflicting information, including officially sanctioned, authoritative information, as well as mixed social and cultural messages, it can be quite difficult to assess which path is "correct." Unfortunately, in some cases, a reasonable and cautious assessment of the evidence can lead an individual to more expensive or less-healthy behaviours, a phenomenon public health experts refer to as "regrettable substitutions" (Scherer et al., 2014).

\section{Discussion}

Within this diverse sample of young parents in Greater Vancouver, a variety of healthrelated information practices were observed and described. These information practices interacted with young parents' own adolescent developmental needs and tasks, were shaped by the increasing shift of urban youth and parenting cultures to online interaction, and the twin emphases by the dominant culture on the importance of intensive parenting and the nonnormative nature of young parenting. These study findings may be informative to researchers and practitioners interested in the information practices of youth, of parents, and of health information seekers in settings that share attributes of contemporary urban Canada.

While Savolainen's model of everyday information practices (Savolainen, 2008, p. 65), which informed this study's conceptual approach and interview guide, groups practices within baskets of seeking, use, and sharing, in this study, assessing and otherwise managing information emerged as a major process that involved cognitive, affective, and social elements, whereas sharing functioned more as a form of use than a separate genre of practices. This emphasis on assessment may reflect in part the heavy load of information work placed on new parents by the ideology of intensive parenting, and/or the particular importance of accuracy, credibility, and precision when it comes to health information. While the social and geographic locations of 
study participants shaped their rubrics for information quality and utility assessments, it is also possible that assessment merits consideration as a stand-alone set of everyday information practices more broadly.

When studying a population that has been socially marginalized there is a constant challenge to the researcher to appropriately balance: a) recognition of the differences of experience, values, behaviour, and practices between the marginalized subpopulation and the mainstream, and b) recognition of the similarities and perhaps universality of certain experiences, values, behaviours, and practices that transcend distinctions such as class and racialization. In the case of the current study, young parents in contemporary urban Canada, where teenage pregnancy and parenting is considered by many to be a negative outcome and "risky" behaviour, are also a population heavily composed of youth who are also socially marginalized along lines of class, ethnicity, immigrant status, and education.

In an aim to both acknowledge the uniqueness of participants' experiences and challenges, and their resilience and humanity, I have attempted to refrain from judgement of information practices that might be perceived by some as "negative" (e.g., information withholding or avoidance). As a result, the descriptions of health information practices here may be at once deeply contextualized and sufficiently high-level to be transferrable to other populations and settings. As part of this duality, however, questions necessarily emerge regarding the applicability of the Chatman's concepts of information poverty and small worlds to the study population. These theories were based in research with social outsiders (e.g., women in prison, people living in poverty) who were also information poor compared with members of the societal mainstream. Chatman found that information poor social outsiders engaged in self-protective behaviours such as secrecy and deception, in situations when mainstream culture insiders had the 
power to manage and withhold information, and whose insider information was not always credible or relevant to outsiders in the context of their own lives. People living in information poverty also managed their own information tightly in an attempt to control the risks of exposure of their own weaknesses. Based on this study's findings, Chatman's theory of information poverty appears to apply in some ways to the practices of young mothers in this study, but in other ways there are differences. Young parents in this study did manage their own release of personal information in exchange for health and social services, and at times colluded with their portrayal as ignorant, aware that their expertise would not be welcomed or valued by experts. However, most of the study population lived up to their generation's reputation for connectedness and digital fluency, and were readily able to access information from beyond the bounds of their immediate social worlds via the Internet, potentially reducing some of the access issues and informational imbalances that have been found to exist with other populations and settings.

\section{Strengths and Limitations}

The large amount of ethnographic fieldwork over more than a year's time, and the triangulation of interview data with field observations by a researcher embedded within YPPs, allowed this analysis to generate in-depth understanding of rich qualitative data. An example of this was observation of subversive information seeking in context, which had not been described by participants in interviews, but which could be then probed in subsequent interviews with the same participants. Building trust with participants via multiple data collection visits over time also strengthened the researcher-participant relationship, which was evident in follow-up interviews. Given the extent to which these study findings are rooted in specific and triangulated naturalistic data, they are likely applicable to a diversity of individuals across a variety of 
settings. However, the participants are not necessarily representative of all youth, parents, or even young parents, so transferring findings to other settings and populations should be done with caution. One way in which the study population was clearly non-representative of all young parents was in the very small number of father participants. Despite efforts in the recruitment process to be gender inclusive, recruitment methods focusing on young parent services primarily reached mothers. Recruiting primarily through programs that serve young parents potentially introduced sampling bias in the form of under-representation of young parents who were less involved with social and educational services. Young parents who were reached through recruitment yet chose not to participate in interviews may share attributes that are not represented by interview participants, potentially introducing non-response bias. Additionally, those parents who did participate may have selectively disclosed information due to social desirability bias, oriented toward the researcher or the service providers at the fieldwork sites. Finally, while every effort was made to sustain the diversity, complexity, and context-laden nature of the experiences of young parents during the analysis and writing-up of this study, the nature of the study did to some extent lump together young parents as a population of interest, and it is important to emphasize the heterogeneity of this population.

\section{Theoretical Implications}

In addition to the finding that health information assessment and management practices were both significant work for participants and substantially distinct from practices considered to be information use, and the assertion that information sharing and mediating may be conceptualized as forms of information use, certain information practices were identified within this study, and merit future investigation. Among these were subversive information seeking about taboo topics, exemplified in this study by practices of complaining and sharing "TMI," and 
defensive information seeking and storage, used by young mothers in this study to provide evidence of their fitness as parents in a climate that valued "intensive mothering" practices such as formal childbirth education and record-keeping. While these were both observed in use by young mothers in urban Canada, it is likely that other populations in other settings may engage in similar practices on health, parenting, or other topics. Some past work has taken on youthassociated, often-digital culture practices such as "oversharing” (boyd, 2014; Jarvis, 2011), which shares some aspects of subversive seeking, particularly seeking via sharing of TMI. Defensive seeking, while not included as a strategy of Chatman's original theory of information poverty (Chatman, 1996) may serve as an extension of information poverty practices in the information age. Future work might focus in on these practices among multiple populations and develop specific theory to address the ways such social information practices develop and function.

\section{Practice Implications}

These study findings may be of use in informing and structuring health information interventions intended to work in concert with young parents' own information practices. Understanding the diversity among young parents, including cultural norms as well as a range of information seeking, assessment, and sharing practices, may be of use in tailoring information programs and services for this population. For example, programs might consider the importance of online information being accessible to mobile devices, of visually-oriented print materials, for parents who are young teens or have less formal education, and of hiring staff who will be perceived as relatable and trustworthy information sources.

\section{Future Work}


Two main questions emerge pointing to future work based on this study: that of potential interactions and intersections between these findings and other models and theories of information behavior and practices, and that of the applicability of the findings beyond the study population. Understanding of these young parents' health information practices was influenced by both the adolescent developmental "selves" identified in Agosto and Hughes-Hassell's (2006) model of the everyday life information needs of urban teenagers, and the information seeking types illustrated by McKenzie's (2003) model of information practices in everyday life information seeking. Deeper exploration into the interactions among adolescent developmental tasks, types of information seeking, and health information practices more broadly could shed more light on the importance of life stage and personality factors on health decisions and behaviours in specific cultural contexts. Additional work could explore the complementarity of specific models of information behaviours, such as Kuhlthau's information search process (Kuhlthau, 1991), which depicts some of the more formalized seeking processes in which participants engaged, and Erdelez's functional model of information encountering (Erdelez, 1999), which portrays the encountering process in depth.

Future research exploring the applicability of the study findings beyond young parents and to topics that are not health-related, would also be valuable. The current study focused on a population that has been socially marginalized and thus treated differently from the mainstream by many information sources and systems. As a rigorous qualitative exploration, this investigation delved deeply into the experiences of participants in their particular contexts. However, certain practices on the part of participants - such as subversive seeking — may be more indicative of intensive parenting, health information practices of larger populations, or may even be more broadly applicable within contemporary Western cultures. Further work 
investigating (non-parenting) youth everyday information practices, parental information practices (perhaps with a greater emphasis on fathers or on rural parents), and everyday health information practices for self and non-child dependents will enable testing of the applicability, extensibility, and scalability of these findings to other research questions, settings, and populations.

\section{Conclusion}

This grounded theory study investigated the health related information practices of a group of young parents, a population highly targeted by health information interventions yet whose information practices have not previously been explored. The diverse study population was highly networked via mobile technology and strongly engaged in health information seeking, employing a variety of strategies to meet proactive and reactive information needs. While access to information was rarely a barrier, assessment of the large quantity of health-related information with which young parents were inundated posed challenges that available information services were not always equipped to recognize or address. Health information and misinformation were therefore both used to inform decisions and behaviour. For optimal health information uptake, resources and programs for young parents would ideally be not only factually accurate, but culturally appropriate, well-timed, visually engaging, and delivered by a trusted source. 


\section{References}

Abrahamson, J.A. and Fisher, K.E. (2007), “'What's past is prologue': towards a general model of lay information mediary behaviour", Proceedings of the Sixth International Conference on Conceptions of Library and Information Science, Vol. 12 no 4, presented at the Featuring the Future, Information Research, Borås, Sweden, available at: http://www.informationr.net/ir/12-4/colis/colis15.html (accessed 22 October 2014).

Abrahamson, J.A., Fisher, K.E., Turner, A.G., Durrance, J.C. and Turner, T.C. (2008), “Lay information mediary behavior uncovered: exploring how nonprofessionals seek health information for themselves and others online", Journal of the Medical Library Association: JMLA, Vol. 96 No. 4, pp. 310-323.

Afflerback, S., Carter, S.K., Anthony, A.K. and Grauerholz, L. (2013), “Infant feeding consumerism in the age of intensive mothering and risk society", Journal of Consumer Culture, p. 1469540513485271.

Agosto, D.E. (2011), “Young Adults' Information Behavior: What We Know So Far and Where We Need to Go from Here", The Journal of Research on Libraries and Young Adults, available at: http://www.yalsa.ala.org/jrlya/2011/11/young-adults\%E2\%80\%99information-behavior-what-we-know-so-far-and-where-we-need-to-go-from-here/.

Agosto, D.E. and Abbas, J. (2011), Teens, Libraries, and Social Networking What Librarians Need to Know, Libraries Unlimited, Santa Barbara, Calif.

Agosto, D.E., Abbas, J. and Naughton, R. (2012), “Relationships and social rules: Teens' social network and other ICT selection practices", Journal of the American Society for Information Science and Technology, Vol. 63 No. 6, pp. 1108-1124. 
Agosto, D.E. and Hughes-Hassell, S. (2006), “Toward a model of the everyday life information needs of urban teenagers, Part 2: Empirical model", Journal of the American Society for Information Science and Technology, Vol. 57 No. 11, pp. 1418-1426.

Agosto, D.E. and Hughes- Hassell, S. (2006), "Toward a model of the everyday life information needs of urban teenagers, part 1: Theoretical model", Journal of the American Society for Information Science and Technology, Vol. 57 No. 10, pp. 1394-1403.

Barman-Adhikari, A. and Rice, E. (2011), "Sexual Health Information Seeking Online Among Runaway and Homeless Youth”, Journal of the Society for Social Work and Research, Vol. 2 No. 2, pp. 88-103.

Bates, M.J. (2010), “Information Behavior", Encyclopedia of Library and Information Sciences, CRC Press, New York.

Bernier, A. (2007), 'Not broken by someone else's schedule: On joy and young adult information-seeking”, in Chelton, M.K. and Cool, C. (Eds.), Information-Seeking Behavior II: Theories, Models, and Issues., Scarecrow Press, Lanham, MD.

Bonell, C. (2004), "Why is teenage pregnancy conceptualized as a social problem? A review of quantitative research from the USA and UK", Culture, Health \& Sexuality, Vol. 6 No. 3, pp. $255-272$.

Bourdieu, P. (1977), Outline of a Theory of Practice, translated by Nice, R., Cambridge University Press.

Bourdieu, P. (1998), Practical Reason: On the Theory of Action, Stanford University Press, Palo Alto, California.

boyd, danah. (2014), It's Complicated: The Social Lives of Networked Teens, Yale University Press, New Haven. 
boyd, danah and Marwick, A.E. (2011), Social Privacy in Networked Publics: Teens'Attitudes, Practices, and Strategies, SSRN Scholarly Paper No. ID 1925128, Social Science Research Network, Rochester, NY, available at: http://papers.ssrn.com/abstract=1925128 (accessed 8 April 2014).

Burek Pierce, J. (2007), "Young adult sexual and reproductive health information needs", in Chelton, M.K. and Cool, C. (Eds.), Youth Information-Seeking Behavior II: Context, Theories, Models, and Issues, Scarecrow Press, pp. 63-91.

Camic, C., Gross, N. and Lamont, M. (2011), Social Knowledge in the Making, University of Chicago Press.

Carey, R.F., McKechnie, L.E.F. and McKenzie, P.J. (2001), “Gaining access to everyday life information seeking”, Library \& Information Science Research, Vol. 23 No. 4, pp. 319334.

Case, D.O. (2006), Looking for Information, Second Edition: A Survey of Research on Information Seeking, Needs, and Behavior, 2nd ed., Academic Press.

Case, D.O., Andrews, J.E., Johnson, J.D. and Allard, S.L. (2005), “Avoiding versus seeking: the relationship of information seeking to avoidance, blunting, coping, dissonance, and related concepts", Journal of the Medical Library Association, Vol. 93 No. 3, pp. 353362.

Charmaz, K. (2007), Constructing Grounded Theory: A Practical Guide through Qualitative Analysis, Sage Publications, Thousand Oaks, CA.

Charmaz, K. (2009), “Constructivist grounded theory methods”, in Morse, J.M. (Ed.), Developing Grounded Theory: The Second Generation, Left Coast Press, Walnut Creek, CA, pp. 127-154. 
Chatman, E.A. (1991), "Life in a small world: Applicability of gratification theory to information-seeking behavior", Journal of the American Society for Information Science, Vol. 42 No. 6, pp. 438-449.

Chatman, E.A. (1996), "The impoverished life- world of outsiders", Journal of the American Society for Information Science, Vol. 47 No. 3, pp. 193-206.

Dervin, B. (1992), “From the mind's eye of the 'user': The sense-making qualitative-quantitative methodology", Qualitative Research in Information Management, Libraries Unlimited, pp. 61-84.

Dervin, B. and Nilan, M. (1986), “Information needs and uses”, in Williams, M.E. (Ed.), Annual Review of Information Science and Technology, Vol. 21, Knowledge Industry, Inc., White Plains, NY, pp. 3-33.

Erdelez, S. (1999), “Information Encountering: It's More Than Just Bumping into Information”, Bulletin of the American Society for Information Science and Technology, Vol. 25 No. 3, pp. 26-29.

Fisher, K.E. (2005), "Information Grounds”, in Fisher, K.E., Erdelez, S. and McKechnie, L. (Eds.), Theories of Information Behavior, Information Today, Medford, NJ, pp. 185-190.

Fisher, K.E. and Landry, C.F. (2007), "Understanding the information behavior of stay-at-home mothers through affect", in Nahl, D. and Bilal, D. (Eds.), Information and Emotion: The Emergent Affective Paradigm in Information Behavior Research and Theory, Information Today, Inc., Medford, NJ, pp. 211-234.

Fisher, K.E. and Naumer, C.M. (2006), "Information Grounds: Theoretical Basis and Empirical Findings on Information Flow in Social Settings", New Directions in Human Information Behavior, pp. 93-111. 
Flanagan, J.C. (1954), “The critical incident technique”, Psychological Bulletin, Vol. 51 No. 4.

Fox, B. (2006), “Motherhood as a class act: The many ways in which 'intensive mothering' is entangled with social class", in Bezanson, K. (Ed.), Social Reproduction: Feminist Political Economy Challenges Neo-Liberalism, McGill-Queen’s University Press, Montreal, QC, CAN, available at: http://site.ebrary.com/lib/alltitles/docDetail.action?docID=10558945 (accessed 9 March 2015).

Fraser, N. (1990), Unruly Practices: Power, Discourse and Gender in Contemporary Social Theory, Polity Press.

Fry, J. (2006), "Scholarly research and information practices: a domain analytic approach", Information Processing \& Management, Vol. 42 No. 1, pp. 299-316.

Furstenberg, F.F. (1976), “The Social Consequences of Teenage Parenthood”, Family Planning Perspectives, Vol. 8 No. 4, pp. 148-164.

Glaser, B.G. (1965), “The Constant Comparative Method of Qualitative Analysis”, Social Problems, Vol. 12 No. 4, pp. 436-445.

Glaser, B.G. and Strauss, A. (1967), The Discovery of Grounded Theory: Strategies for Qualitative Research, Aldine Transaction.

Gray, N.J., Klein, J.D., Noyce, P.R., Sesselberg, T.S. and Cantrill, J.A. (2005), “Health information-seeking behaviour in adolescence: the place of the internet", Social Science \& Medicine, Vol. 60 No. 7, pp. 1467-1478.

Greyson, D. (2013), “Information World Mapping: A Participatory, Visual, Elicitation Activity for Information Practice Interviews", Proceedings of the 76th ASIS\&T Annual Meeting: 
Beyond the Cloud: Rethinking Information Boundaries, Association for Information Science \& Technology, Silver Springs, MD, USA, p. 106:1-106:4.

Hawe, P., Ruggiero, E.D. and Cohen, E. (2012), "Frequently Asked Questions About Population Health Intervention Research”, Can J Public Health, Vol. 103 No. 6, pp. e468-e471. Hays, S. (1996), The Cultural Contradictions of Motherhood, Yale University Press, New Haven. Hill, P., Uris, P. and Bauer, T. (2007), “The Nurse-Family Partnership: a policy priority. In-home nurse visits are cost-effective and evidence based", The American Journal of Nursing, Vol. 107 No. 11, pp. 73-75.

Hottes, T.S., Farrell, J., Bondyra, M., Haag, D., Shoveller, J.A. and Gilbert, M. (2012), “InternetBased HIV and Sexually Transmitted Infection Testing in British Columbia, Canada: Opinions and Expectations of Prospective Clients", Journal of Medical Internet Research, Vol. 14 No. 2, p. e41.

Jarvis, J. (2011), Public Parts: How Sharing in the Digital Age Improves the Way We Work and Live, 1st Simon \&amp; Schuster hardcover ed., Simon \&amp; Schuster, New York. Johannisson, J. and Sundin, O. (2007), "Putting Discourse to Work: Information Practices and the Professional Project of Nurses", The Library Quarterly, Vol. 77 No. 2, pp. 199-218. Kelly, D.M. (2007), "Young Mothers, Agency and Collective Action: Issues and Challenges”, Journal of the Motherhood Initiative for Research and Community Involvement, Vol. 9 No. 1, available at: http://pi.library.yorku.ca/ojs/index.php/jarm/article/view/5131 (accessed 5 February 2012).

Kemppainen, J.K. (2000), “The critical incident technique and nursing care quality research", Journal of Advanced Nursing, Vol. 32 No. 5, pp. 1264-1271. 
Kindig, D. and Stoddart, G. (2003), “What Is Population Health?”, American Journal of Public Health, Vol. 93 No. 3, pp. 380-383.

Kuhlthau, C.C. (1991), “Inside the search process: Information seeking from the user's perspective", Journal of the American Society for Information Science, Vol. 42 No. 5, pp. $361-371$.

Landry, C.F. and Fisher, K.E. (2006), "The missing piece: Affect and the information behavior of stay-at-home mothers", Proceedings of the American Society for Information Science and Technology, Vol. 43 No. 1, pp. 1-6.

Loudon, K.J., Buchanan, S. and Ruthven, I. (2016), “The everyday life information seeking behaviours of first-time mothers", Journal of Documentation, Vol. 72 No. 1, available at: https://pure.strath.ac.uk/portal/en/publications/the-everyday-life-information-seekingbehaviours-of-first-time-mothers(f41c5f68-d739-4048-81d7-9c74d14ba948).html (accessed 22 September 2015).

Luker, K. (1997), Dubious Conceptions: The Politics of Teenage Pregnancy, Harvard University Press.

Lupton, D. (2014), Risk, 2nd ed., Routledge, Abingdon, Oxon ; New York, available at: http://ezproxy.library.ubc.ca/login?url=http://www.ubc.eblib.com/EBLWeb/patron/?target =patron\&extendedid=P_1183158_0 (accessed 7 March 2015).

Marmot, M. and Wilkinson, R. (2005), Social Determinants of Health, Oxford University Press, New York.

McKenzie, P.J. (2002), “Communication barriers and information-seeking counterstrategies in accounts of practitioner-patient encounters”, Library \& Information Science Research, Vol. 24 No. 1, pp. 31-47. 
McKenzie, P.J. (2003), “A model of information practices in accounts of everyday-life information seeking”, Journal of Documentation, Vol. 59 No. 1, pp. 19-40.

McKenzie, P.J. (2004), "Positioning Theory and the Negotiation of Information Needs in a Clinical Midwifery Setting", Journal of the American Society for Information Science and Technology, Vol. 55 No. 8, pp. 685-694.

McKenzie, P.J. (2006a), “The seeking of baby-feeding information by Canadian women pregnant with twins", Midwifery, Vol. 22 No. 3, pp. 218-227.

McKenzie, P.J. (2006b), "Mapping textually mediated information practice in clinical midwifery care", in Amanda Spink and Cole, C. (Eds.), New Directions in Human Information Behavior, Springer, Netherlands, pp. 73-92.

McKenzie, P.J. (2009), “Informing choice: The organization of institutional interaction in clinical midwifery care", Library \& Information Science Research, Vol. 31 No. 3, pp. 163-173.

McKenzie, P.J. (2010), “Informing relationships: small talk, informing and relationship building in midwife-woman interaction”, Information Research, Vol. 15 No. 1, p. n.p.

Mejdoubi, J., Heijkant, S.C.C.M. van den, Leerdam, F.J.M. van, Heymans, M.W., Crijnen, A. and Hirasing, R.A. (2015), "The Effect of VoorZorg, the Dutch Nurse-Family Partnership, on Child Maltreatment and Development: A Randomized Controlled Trial", PLOS ONE, Vol. 10 No. 4, p. e0120182.

Nurse Family Partnership. (2011), "Nurse-Family Partnership Model Elements”, Nurse Family Partnership, available at: http://www.nursefamilypartnership.org/Communities/Modelelements (accessed 22 March 2015). 
Papen, U. (2013), “Conceptualising information literacy as social practice: a study of pregnant women's information practices", Information Research, Vol. 18 No. 2, available at: http://informationr.net/ir/18-2/paper580.html\#.Ub0_YNicGSo (accessed 16 June 2013).

Raphael, D. (2009), Social Determinants of Health: Canadian Perspectives, Canadian Scholars' Press.

Reckwitz, A. (2002), “Toward a Theory of Social Practices A Development in Culturalist Theorizing”, European Journal of Social Theory, Vol. 5 No. 2, pp. 243-263.

Rieh, S.Y. (2009), “Credibility and Cognitive Authority of Information”, Encyclopedia of Library and Information Sciences, Third Edition, Taylor \& Francis, pp. 1337-1344.

Robling, M., Bekkers, M.-J., Bell, K., Butler, C.C., Cannings-John, R., Channon, S., Martin, B.C., et al. (2016), "Effectiveness of a nurse-led intensive home-visitation programme for first-time teenage mothers (Building Blocks): a pragmatic randomised controlled trial”, The Lancet, Vol. 387 No. 10014, pp. 146-155.

Romagnoli, A. and Wall, G. (2012), “'I know I'm a good mom': Young, low-income mothers’ experiences with risk perception, intensive parenting ideology and parenting education programmes", Health, Risk \& Society, Vol. 14 No. 3, pp. 273-289.

Savolainen, R. (1995), "Everyday life information seeking: Approaching information seeking in the context of "way of life", Library \& Information Science Research, Vol. 17 No. 3, pp. 259-294.

Savolainen, R. (2005), "Everyday life information seeking”, Theories of Information Behavior, Information Today, Inc., pp. 143-152. 
Savolainen, R. (2007), “Information Behavior and Information Practice: Reviewing the 'Umbrella Concepts' of Information- Seeking Studies”, The Library Quarterly, Vol. 77 No. 2, pp. 109-132.

Savolainen, R. (2008), Everyday Information Practices: A Social Phenomenological Perspective, Scarecrow Press, Lanham, MD.

Savolainen, R. (2009), “Everyday Life Information Seeking”, Encyclopedia of Library and Information Sciences, Third., Taylor \& Francis, New York, pp. 1780-1789.

Scherer, L.D., Maynard, A., Dolinoy, D.C., Fagerlin, A. and Zikmund-Fisher, B.J. (2014), “The psychology of 'regrettable substitutions': examining consumer judgements of Bisphenol A and its alternatives", Health, Risk \& Society, Vol. 16 No. 7-8, pp. 649-666.

Shoveller, J.A. and Johnson, J.L. (2006), "Risky groups, risky behaviour, and risky persons: Dominating discourses on youth sexual health”, Critical Public Health, Vol. 16 No. 1, pp. $47-60$.

Shoveller, J.A., Knight, R., Davis, W., Gilbert, M. and Ogilvie, G. (2012), “Online sexual health services: examining youth's perspectives", Canadian Journal of Public Health. Revue Canadienne de Santé Publique, Vol. 103 No. 1, pp. 14-18.

Talja, S. and Hartel, J. (2007), "Revisiting the user-centred turn in information science research: an intellectual history perspective", Information Research, Vol. 12 No. 4, available at: http://informationr.net/ir/12-4/colis/colis04.html (accessed 22 February 2012).

Talja, S. and McKenzie, P.J. (2007), “Editors’ Introduction: Special Issue on Discursive Approaches to Information Seeking in Context", The Library Quarterly, Vol. 77 No. 2, pp. $97-108$. 
Urquhart, C., Light, A., Thomas, R., Barker, A., Yeoman, A., Cooper, J., Armstrong, C., et al. (2003), "Critical incident technique and explicitation interviewing in studies of information behavior", Library \& Information Science Research, Vol. 25 No. 1, pp. 6388.

Walker, C. (2012), "The Information World of Parents: A Study of the Use and Understanding of Information by Parents of Young Children”, Library Trends, Vol. 60 No. 3, pp. 546-568.

Wilson, P. (1983), Second-Hand Knowledge: An Inquiry into Cognitive Authority, Greenwood Press, Westport, Conn.

Wilson, T.D. (1999), "Models in information behaviour research", Journal of Documentation, Vol. 55, pp. 249-270.

Wilson, T.D. (2000), "Human Information Behavior”, Informing Science, Vol. 3 No. 2, pp. 49-55.

Wilson, T.D. and Savolainen, R. (2009), "The behaviour/practice debate: a discussion prompted by Tom Wilson's review of Reijo Savolainen's Everyday information practices: a social phenomenological perspective. Lanham, MD: Scarecrow Press, 2008.”, Information Research, Vol. 14 No. 2, available at: http://informationr.net/ir/14-2/paper403.html (accessed 24 April 2012).

Zieroth, M. (2007), “Adolescent Pregnancy, Information Seeking and the Construction of Cognitive Authority", presented at the Maternal Health and Well -Being Conference, Association for Research on Mothering, Toronto, ON, available at: http://www.motherhoodinitiative.org/MaternalHealthandWBProgram.pdf.

Zipf, G.K. (1949), Human Behavior and the Principle of Least Effort, Vol. xi, Addison-Wesley Press, Oxford, England. 


\section{Footnotes}

${ }^{1}$ One unpublished student paper was found (Zieroth, 2007), which was delivered at a conference that did not publish full proceedings.

${ }^{2}$ Neighbourhood houses are non-profit community centres offering services such as childcare, seniors' programming, cultural events, and immigrant settlement. An international movement, neighbourhood houses have a network across the province.

${ }^{3}$ Audio recorded interviews were transcribed and accuracy checked by thrice before being provided to interview participants for member-checking. One participant declined consent for audio recording; notes were taken during this interview instead. 